\title{
Rainfall and dry spell occurrence in Ghana: trends and seasonal predictions with a dynamical and a statistical model
}

\author{
Talardia Gbangou $^{1}$ (D) Fulco Ludwig ${ }^{1} \cdot$ Erik van Slobbe $^{1} \cdot$ Wouter Greuell $^{1} \cdot$ Gordana Kranjac-Berisavljevic $^{2}$
}

Received: 12 September 2019 / Accepted: 1 April 2020 / Published online: 23 April 2020

(C) The Author(s) 2020

\begin{abstract}
Improved information on the distribution of seasonal rainfall is important for crop production in Ghana. The predictability of key agro-meteorological indices, namely, seasonal rainfall, maximum dry spell length (MDSL) and dry spell frequency (DSF) was investigated across Ghana (with an interest on the coastal savannah agro-ecological zone). These three variables are relevant for local agricultural water management. A dynamical model (i.e. European Centre for Medium-Range Weather Forecasts (ECMWF) System 4 seasonal forecasts) and a statistical model (i.e. response to sea surface temperatures (SSTs)) were used and analysed using correlation and other discrimination skill metrics. ECMWF-System 4 was bias-corrected and verified with 14 local stations' observations. Results show that differences in variability and skills of the agro-meteorological indices are small between agro-ecological zones as compared to the differences between stations. The dynamic model System 4 explains up to $31 \%$ of the variability of the MDSL and seasonal rainfall indices. Coastal savannah exhibits the highest level of discrimination skills. However, these skills are generally higher for the below and above normal MDSL and seasonal rainfall categories at lead time 0. Similarity in skills for the agro-meteorological indices over the same zones and stations is found both for the dynamical and statistical models. Although System 4 performs slightly better than the statistical model, especially, for dry spell length and seasonal rainfall. For dry spell frequency and longer lead time dry spell length, the statistical model tends to perform better. These results suggest that the agro-meteorological indices derived from System 4' updated versions, corrected with local observations, together with the response to SST information, can potentially support decision-making of local smallholder farmers in Ghana.
\end{abstract}

\section{Introduction}

In Ghana, West Africa, demands for operational predictions of rainfall and related indices are growing to support rural communities (Vitart et al. 2017; Gbangou et al. 2019; Nyadzi et al. 2019). This is especially true where rainfed smallholder farmers are affected by climate variability and change (Mendelsohn et al. 2006; Codjoe et al. 2014; Gbangou et al. 2019). Provision of forecasts of water availability indicators with sufficient accuracy and appropriate lead time can

Electronic supplementary material The online version of this article (https://doi.org/10.1007/s00704-020-03212-5) contains supplementary material, which is available to authorized users.

Talardia Gbangou

talardia.gbangou@wur.nl

1 Water System and Global Change group, Wageningen University \& Research, Wageningen, Netherlands

2 University for Development Studies, Tamale, Ghana potentially improve management for rainfed or semi-rainfed farming systems in Ghana. Seasonal forecast of the likelihood of the growing season's water availability can help inform farmers with long-term planning. For example, the Waterapps research project (www.waterapps.net) aims to develop tailored water information services with and for farmers in peri-urban areas in the urbanizing deltas of Accra, Ghana to improve the water and food security. The project focusses on Ghana's urbanizing delta because of agricultural intensification, water availability issues and the increasing possibilities of farmers to use ICT for climate information service. Also, risks in terms of crop failure due to unexpected rainfall events are growing and hence the need for improved rainfall forecasts is growing too. Therefore, this study focusses on the coastal savannah agro-ecological zone along the delta area (Fig. 1).

There is a need for agro-meteorological forecast information about seasonal rainfall and dry spell occurrences for West African farmers in general (Usman and Reason 2004; Codjoe et al. 2014; Yaro 2013) and more specifically in the coastal savannah of Ghana delta area (Gbangou et al. 2019). This 

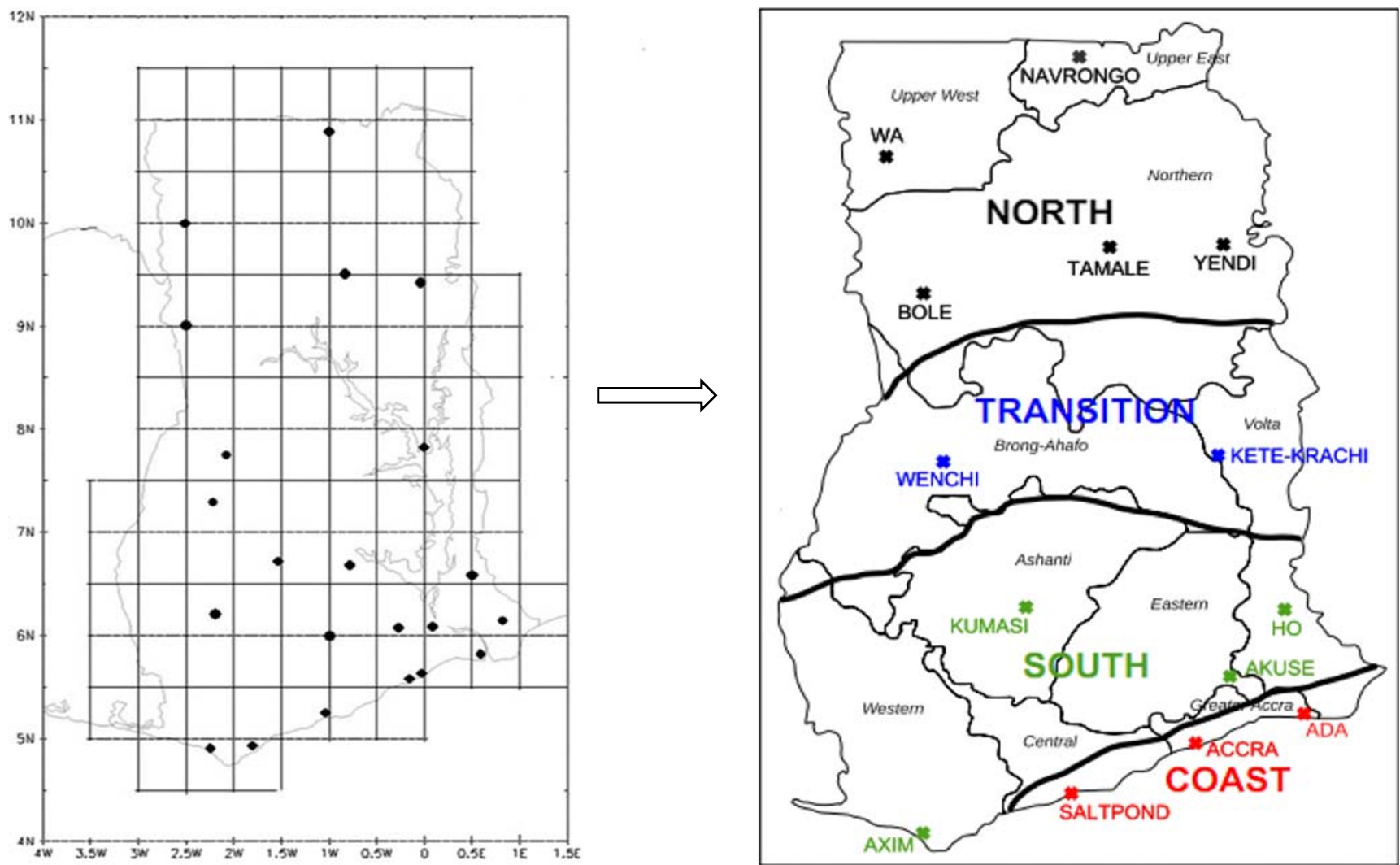

Fig. 1 Map of Ghana showing the location of the 22 gauges stations (left) collected from GMet and sorted into 14 gauges stations (right) across the four main agro-ecological zones previously used in Owusu and Waylen $(2009,2013)$

information can help to improve specific decision-making of many local farmers by optimizing the selection of crop types/ varieties, reducing the cost of land preparation and avoiding crops failure due to premature or late planting time. Dry spells during the growing season have a large impact on crops, and the cumulative rainfall does not fully explain impacts on agriculture, because a few heavy rainfall events may lead to an erroneous impression that a growing season is good (Usman and Reason 2004). According to Usman and Reason (2004), crops are more likely to do well with uniformly spread 'light' rains compared to a few 'heavy' rainfall events interrupted by dry periods. So, the timing of breaks in rainfall events (dry spells) relative to the cropping calendar rather than total seasonal rainfall is fundamental to crop viability and production.

West African rainfall is highly variable on interannual and decadal time scales and is highly correlated with sea surface temperature (SST) (Zhang et al. 2015). Globally, dry conditions over the Sahel and wet conditions over Guinea are associated with positive El Niño-Southern Oscillation (ENSO) SST anomalies of the eastern tropical Pacific, with positive SST anomalies of the Southern Hemisphere Atlantic and with negative anomalies of the Northern Hemisphere Atlantic (the Atlantic dipole) and positive SST anomalies of the tropical Indian Ocean (Folland et al. 1986; Janicot et al. 1998; Rowell 2001; Matthews 2004). The majority of these studies have focussed on large areas (e.g. Sahel and Guinea) of West Africa. Hence, the mentioned rainfall teleconnection may not account for the considerable variability at a more local scale (Diro et al. 2011).

Additionally, global-gridded rainfall products have been shown to exhibit clear ENSO signals over West Africa (Jury et al. 2002; Joly and Voldoire 2009; Alizadeh-Choobari et al. 2018). However, the societal effects of rainfall characteristics are often felt on local scales (Matthews et al. 2013; Wetterhall et al. 2015; Gbangou et al. 2018). For example, small-scale rain-fed agriculture in Ghana or local industrial operations may be crucially dependent on the rainfall in the immediate vicinity but not directly connected to large-scale aggregated rainfall patterns. Hence, the question of whether a large-scale system such as ENSO is 'felt' at the local level and for a specific season of interest can be an important one. No study has yet addressed precisely ENSO effects on dry spells agromet indices during critical growing seasons in Ghana using local station data.

There are also some limitations on seasonal forecast evaluation approaches for the purpose of local communities. More often, large-scale observational products are used as reference for comparison or for bias correction (Fitzpatrick et al. 2015; Vellinga et al. 2013; Wetterhall et al. 2015; Joly and Voldoire 2009) instead of local station data. Although these approaches 
are often justified by the recurent lack of consistent local observations over West Africa, including Ghana (Owusu and Waylen 2009, 2013), findings at large-scale level may have litle benefit for smallholder farmers.

Localized data analysis on dry spell occurrence and seasonal rainfall is important from the point of view of farmers. Farmers need information on these indicators, especially in the first three rainy season months. This type of analysis is yet lacking. March-April-May (MAM) and April-May-June (AMJ) seasons over the coast-south and transition-north agro-ecological zones, respectively (see Fig. 1, Table 1), have been given minimal attention compared to other seasons in Ghana. However, for agricultural applications, these are critical seasons during crops' growing stages as they are highly sensitive to onset, dry spell occurrence and rainfall totals (Gbangou et al. 2019).

This paper examines the skill of ECMWF-System 4 seasonal climate forecasts, a dynamical model, in reproducing the variability of seasonal rainfall and dry spells agrometeorological indices and explores the effect of pre-rainy season SST on these indices over Ghana using local station observations as reference and focusing its analysis on the coastal zone. The response to SST is being considered as a statistical model. Trend and variability in historical observations are explored prior to skill assessment in order to ascertain the climatic conditions and the challenges related to the predictability of the indices.

The study area is Ghana's coastal savannah area, but to identify possible difference between local stations and agroecological zones, we covered the entire Ghana focussing on 14 stations (Fig. 1).

\section{Data}

\subsection{ECMWF-system 4 seasonal climate hindcasts}

ECMWF-System 4 seasonal climate re-forecasts were used. They consist of 15 ensemble members, with initial date on the 1 st of each month and then run for 7 months (i.e. lead months). The re-forecasts (also referred to as hindcasts) extend over the
1981-2010 period. They were acquired from the ECOMS User Gateway (Cofiño et al. (2018); http://meteo.unican.es/ ecoms-udg) and used to verify the performance of System 4 to reproduce dry spell occurrence and seasonal rainfall. Forecasts for periods starting in March and April (i.e. MAM and AMJ seasons) were considered for stations located respectively within the (i) southern and coastal and (ii) transition and northern agro-ecological zones (Table 1). These seasons were selected considering the local cropping calendar and the northward shift with the time of rainfall across Ghana (Sultan and Janicot 2003; Gbangou et al. 2019).

Considering that Ghana has an area of 238,535 km², 14 stations correspond to a mean of $17,038 \mathrm{~km}^{2}$ per station (Fig. 1). This is considered as sparse coverage, according to Masinde et al. (2012), as many models gridded cells (e.g. System 4 has $0.75 \times 0.75$ grid size) may not contain any station within their grid-cell area (Fig. 1). Therefore, instead of interpolating point station rainfall to grid format, which requires a well distributed synoptic stations over Ghana, we rather extracted model gridded data for each of the 14 stations. This was done by applying the nearest neighbour interpolation as described by Manzanas et al. (2014a). Hence, this technique provides relatively good estimates of forecasts time series at each station.

\subsection{Local station data}

Primary data used in this study are the time series of daily rainfall totals from rain gauges at 14 stations out the 22 synoptic stations in Ghana (Fig. 1) over 30 years (1981-2010). These data were used to assess the skill of the forecasts and assess the response to SST anomalies. Datasets were acquired from Ghana Meteorological Agency (GMet). The stations have been grouped according to the four main agroecological zones in Ghana (Fig. 1).

\subsection{Sea surface temperature data}

SST data for February, January and December and for March, February and January lagged months were used to assess the response of the agro-meteorological indices during MAM and
Table 1 System 4 lead month selection per zone (Gbangou et al. 2019)

\begin{tabular}{clc}
\hline Lead time & Costal and southern zone & Transition and northern zone \\
\hline $\begin{array}{c}\text { Lead } \\
\text { month }\end{array}$ & $\begin{array}{c}\text { Forecast start date is 1st March and MAM } \\
\text { season is considered }\end{array}$ & $\begin{array}{c}\text { Forecast start date is 1st April and AMJ season } \\
\text { is considered }\end{array}$ \\
$\begin{array}{c}\text { Lead } \\
\text { month }\end{array}$ & $\begin{array}{c}\text { Forecast start date is 1st February and MAM } \\
\text { season is considered }\end{array}$ & $\begin{array}{c}\text { Forecast start date is 1st March and AMJ } \\
\text { season is considered }\end{array}$ \\
$\begin{array}{c}\text { Lead } \\
\text { month }\end{array}$ & $\begin{array}{c}\text { Forecast start date is 1st January and MAM } \\
\text { season is considered }\end{array}$ & $\begin{array}{c}\text { Forecast start date is 1st February and AMJ } \\
\text { season is considered }\end{array}$ \\
\hline
\end{tabular}


AMJ seasons, respectively. This was done on purpose to explore longer lag time teleconnection and to be consistent with lead months from System 4 (see Table 1). The South Atlantic Tropical SST index (SAT), the Tropical Southern Atlantic index (TSA) and Niño3.4 SST were acquired from NOAA website (https://stateoftheocean.osmc.noaa.gov/sur/) (Reynolds et al. 2002). Niño3.4 SSTs are widely used to characterize ENSO conditions (Huang et al. 2015). The SSTs are averages for the areas shown in Fig. 2. The data cover the seasonal System 4 hindcast period, i.e. 1981-2010. For the remote Niño3.4 SSTs, we also performed analyses for much longer lead times, i.e. SSTs for September, October and November and for October, November and December were related to the MAM and AMJ agro-meteorological indices, respectively. However, these results are only presented in the Supplemental.

\section{Methods}

The area of interest for this study is the coastal savannah area. However, in order to analyse possible differences between large (i.e. entire Ghana) and local (i.e. station and agroecological zones) scale, we compared outcomes with all selected stations in Ghana.

\subsection{Bias correction}

System 4 seasonal hindcasts were bias-corrected against reference GMet observations following the quantile mapping bias correction method. For each station, the method adjusts the forecasted rainfall (System 4) to the observed rainfall (GMet) by matching the cumulative density functions (CDF) of daily rainfall (Gudmundsson et al. 2012; Gudmundsson 2016). The method is proven to be successful in many hydrological and climate impact studies (Maurer and Hidalgo 2008; Li et al. 2010; Wetterhall et al. 2012; Themeß1 et al. 2012; Cooper 2019) as well as in medium-range (Voisin et al. 2010) and seasonal forecasts (Wood et al. 2002).

Wetterhall et al. (2015) demonstrated that this bias correction technique can improve the skill of dry spell length and frequency in comparison with the use of raw forecasts. In a previous study, Ogutu et al. (2017) showed that bias correction does not necessarily improve the skill of rainfall prediction. Therefore, in order to check the bias correction sensitivity, we also analysed un-corrected forecasts. The results were very similar compared to bias-corrected forecasts in terms of skills and were in agreement with the study of Manzanas et al. (2019). However, only bias-corrected results are presented and discussed in this paper. Furthermore, we checked the need for frequency adaptation correction, which is required when the predicted frequency of dry days in the model is larger than the observed one (Themeß1 et al. 2012). In all of our cases, the frequency of dry days was higher in the model than in the observations, so this correction was not made in the present study (see Supplemental 2, Table S1).

\subsection{Definition of the agro-meteorological indices}

The dry spell occurrence definition was adopted from Usman and Reason (2004). During the rainy season, it is not expected that precipitation will occur on a daily basis. However, when breaks in between rains spells are prolonged, plants may wilt and die or have reduced yield. Breaks of equal to or more than 15 days are considered serious anomalies (Adefolalu 1988; Barronfiño 2004). Here, we define the number or frequency

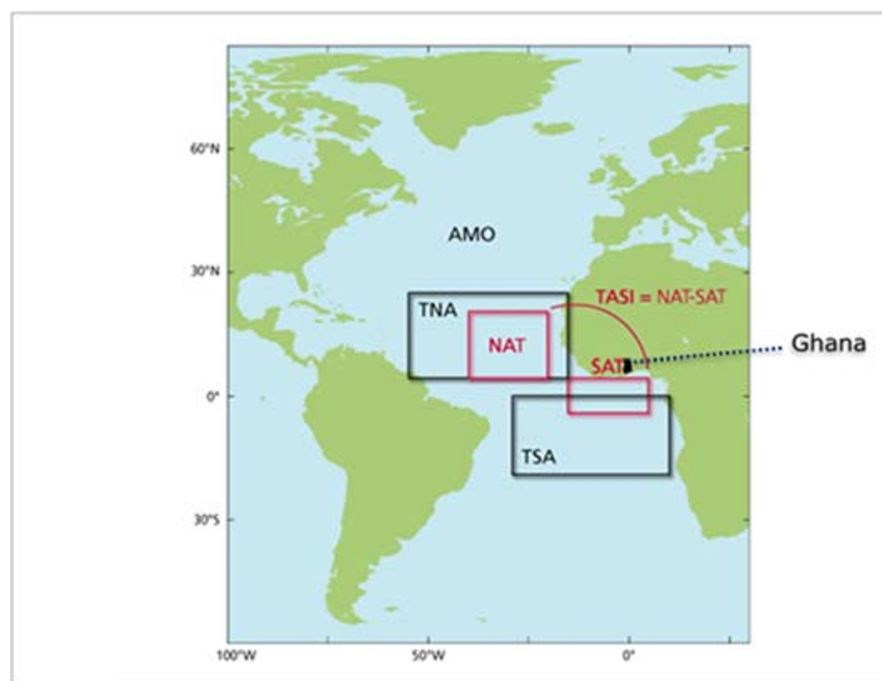

Fig. 2 South Atlantic Tropical SST index (SAT), Tropical Southern Atlantic index (TSA) and Niño3.4 SST box locations. SAT-SST anomalies are in the box $15^{\circ} \mathrm{W}-5^{\circ} \mathrm{E}, 5^{\circ} \mathrm{S}-5^{\circ} \mathrm{N}$. TSA-SST anomalies are in the

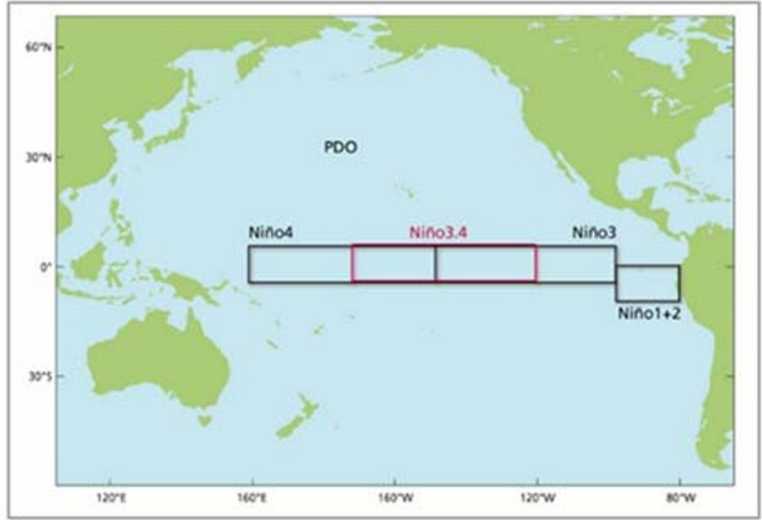

box $30^{\circ} \mathrm{W}-10^{\circ} \mathrm{E}, 20^{\circ} \mathrm{S}-\mathrm{EQ} .4$. Niño3.4-SST anomalies are in the box $170^{\circ} \mathrm{W}-120^{\circ} \mathrm{W}, 5^{\circ} \mathrm{S}-5^{\circ} \mathrm{N}$ 
of dry spell and the longest or maximum dry spell length as follows:

- Longest/maximum dry spell: the largest number of consecutive days during which the rainfall is less than $1 \mathrm{~mm} /$ day over the season.

- Frequency/number of dry spells: the number of dry spells with a length of more than 5 days during which precipitation is less than $1 \mathrm{~mm} /$ day over the season.

- Total seasonal rainfall: the sum of rainfall over the season.

Seasons are defined as March-April-May for the southcoast and April-May-June for the transition-north agroecological zones.

\subsection{Skill assessment metrics of the dynamical model}

Different metrics for assessing the forecasts usefulness for decision making were computed. Seasonal rainfall and dry spell occurrence agro-meteorological indices, derived from System 4 ensemble forecasts, were then verified against GMet observations using (i) Pearson correlation with the ensemble mean (EnsCorr), (ii) the generalized discrimination score for ensemble forecasts (Ens2AFC) (Weigel and Mason 2011) and (iii) relative operating characteristic skill score (ROCSS) computed from the ROC area (Jolliffe and Stephenson 2012). All the three metrics, globally, show the discrimination ability of the forecasts. EnsCorr is a measure of variability and measures how well the forecast anomalies correspond to the observed anomalies over the hindcast period 1981-2010 at each station. Significant correlations indicate that System 4, at least partly, reproduced the variability of observed indices.

Ens2AFC quantified globally, whether a set of observed agro-meteorological indices can be correctly discriminated by the corresponding forecasts (i.e. it is a measure of the skill attribute of discrimination). Positively skilled forecasts will show Ens2AFC > 0.5 (Mason 2013). The ROCSS metric plays the same role as Ens2AFC but gives more details at tercile category level (i.e. below normal, normal and above normal categories). A ROCSS $>0$ for a specific category indicates forecasts with positive skill for discriminating forecast categories (i.e. better than the climatology) (Mason 2013). The ROCSS metric is conditioned on the observations and often needs the reliability diagram, as a partner, which is conditioned on the forecast (i.e. given that an event was predicted, what was the outcome?). The reliability diagram measures how well the predicted probabilities of an event correspond to their observed frequencies.

All the skill metrics were computed using R-packages 'Specs Verification' (Siegert 2017) and 'Easy Verification' (MeteoSwiss 2017). These metrics and packages have been widely used to evaluate the skill of the climate predictions (Cofiño et al. 2018; Manzanas et al. 2018; Ogutu et al. 2017).

\subsection{Analysis of the skills of the statistical model}

The response of agro-meteorological indices (i.e. maximum dry spell length (MDSL), dry spell frequency (DSF) and seasonal rainfall) to SST was expressed using a statistical model (i.e. linear regression) driven by SST indices to assess the predictability. This was done using the (i) two SST indices of relatively nearby areas, namely the South Atlantic index (SAT) and the TSA and (ii) one index of a more remote area, namely the Tropical Pacific Niño index (Niño3.4) (Fig. 2). The statistical forecasts were obtained using a linear regression model between observed agro-meteorological indices and SSTs for individual months (i.e. in a univariate mode). This regression was done in a leave-one-year-out crossvalidation mode. Then, the observed agro-meteorological indices from GMet were correlated with the forecasted ones derived from the statistical model over the period 19812010 and at individual stations across the agro-ecological zones. We recall that the agro-meteorological indices were computed for MAM over the coast-south and for AMJ season over the transition-north agro-ecological zones. To assess the effect of lead time, SST data for February, January, December and for March, February and January were considered for the coast-south (i.e. MAM season) and transition-north (i.e. AMJ season) agro-ecological zones, respectively.

\subsection{Statistical trend, variability and significance analyses}

Several statistical significance tests were applied. The MannKendall test analysis of linear trend significance was carried out on observed agro-meteorological indices. This method is proven to be robust for trend analyses of time series (Partal and Kahya 2006; Obot et al. 2010; Manzanas et al. 2014a). The coefficient of variation $(\mathrm{Cv})$ was used as a measure interannual variability as suggested by Obarein and Amanambu (2019). The $t$ test was used to determine both the (i) significance of correlation relationships between the dynamical forecasts System 4 and GMet derived agro-meteorological indices and the (ii) significance of correlation relationships between statistical forecasts driven by SST and GMet-derived agrometeorological indices. The relation is significant when, for an infinite number of tests, one out of 10 ( $p$ threshold of 0.10 ) is found.

The term 'skilful' forecast is used for positive and significant EnsCorr and ROCSS throughout the paper. Considering that Ens2AFC metric does not have a build-in test for significance at individual stations as for the EnsCorr and ROCSS (Weigel and Mason 2011), a binomial distribution test was 
used alternatively to identify lead time with significant forecasts.

\section{Results}

\subsection{Observed trend and variability of dry spell occurrence and seasonal rainfall}

Observed trends of the agro-meteorological indices, over 1981-2010 period, generally, show no clear significant decreasing and increasing patterns for MAM and AMJ seasons (Table 2) except for 4 stations out of the 14 stations. These 4 stations with significant trend are Ada, Akuse, Wa and Yendi. MDSL at Ada is significantly increasing implying that the prolonged dry spells have increased $(p<0.10)$. DSF at Akuse shows a decreasing pattern with $90 \%$ confidence level as well, implying that the frequency of dry spells has reduced in that location. Seasonal rainfall significantly increased at Wa and Yendi.

The mean and relative variability of MDSL, DSF and seasonal rainfall varies by location and by agro-ecological zones (Fig. 3; Table 2). Average MDSL and DSF are higher along the coast and in northern Ghana compared to the south and transition zones. Southern and transition zones have the highest average seasonal rainfall. MDSL in the overall coastal and northern Ghana have higher relative variability compared to the south and transition zones. The coastal savannah also has the highest variability of seasonal rainfall.

\subsection{Ability of System 4 in reproducing dry spell occurrence and seasonal rainfall (dynamical model)}

The EnsCorr for the three agro-met indices (i.e. MDSL, DSF and seasonal rainfall) range from -0.35 to 0.56 for different lead times and different stations across Ghana (Fig. 4). This
Table 2 Mean, coefficient of variation and trend significance test of the agro-meteorological indices for the 14 stations over 1981-2010. Asterisk indicates significant trend at $95 \%$ confidence. Positive (blue bar) and negative (i.e. red bar) tau indicate increasing and decreasing trends, respectively. Bold values indicate the average over each agro-ecological zone

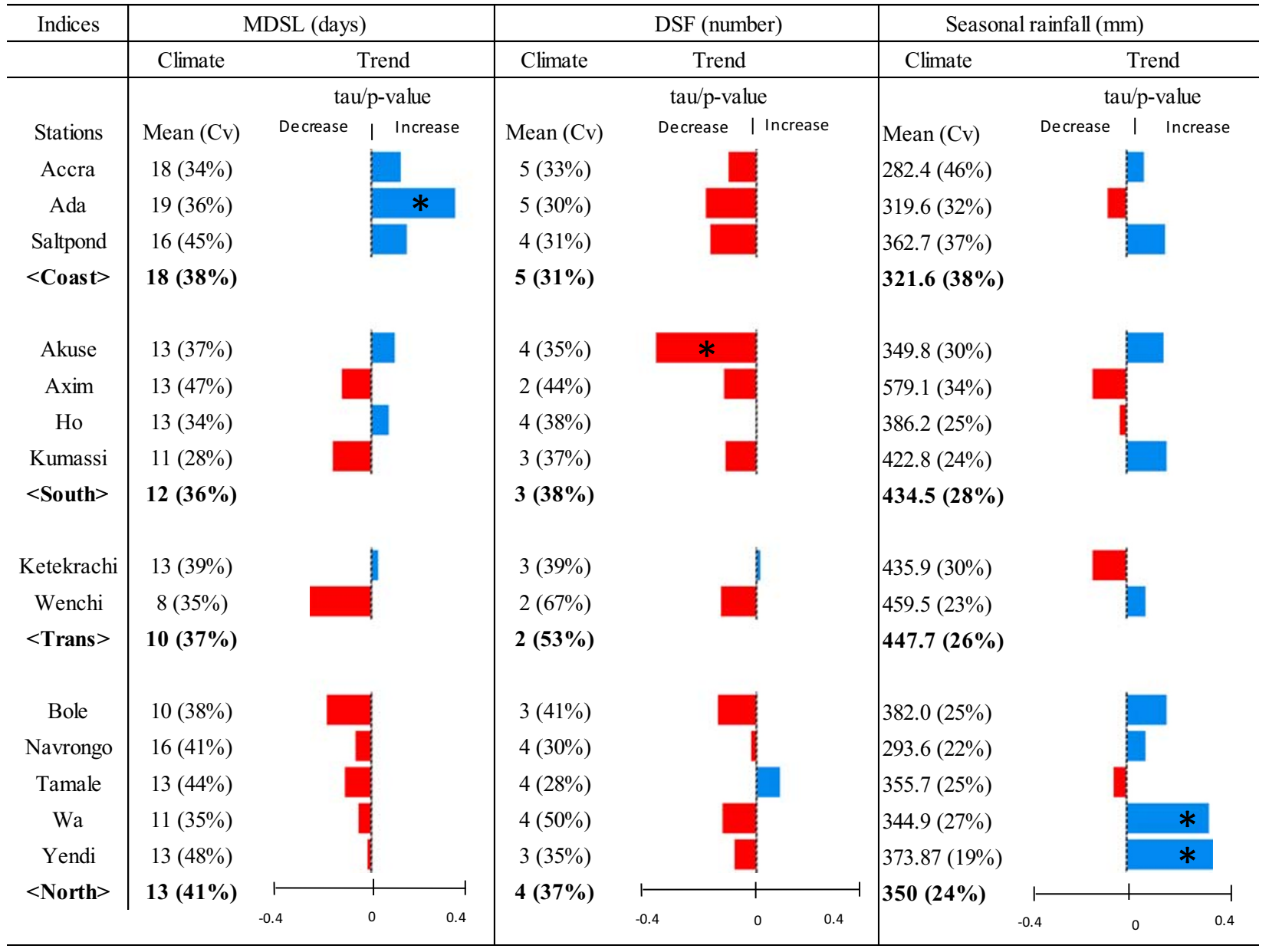



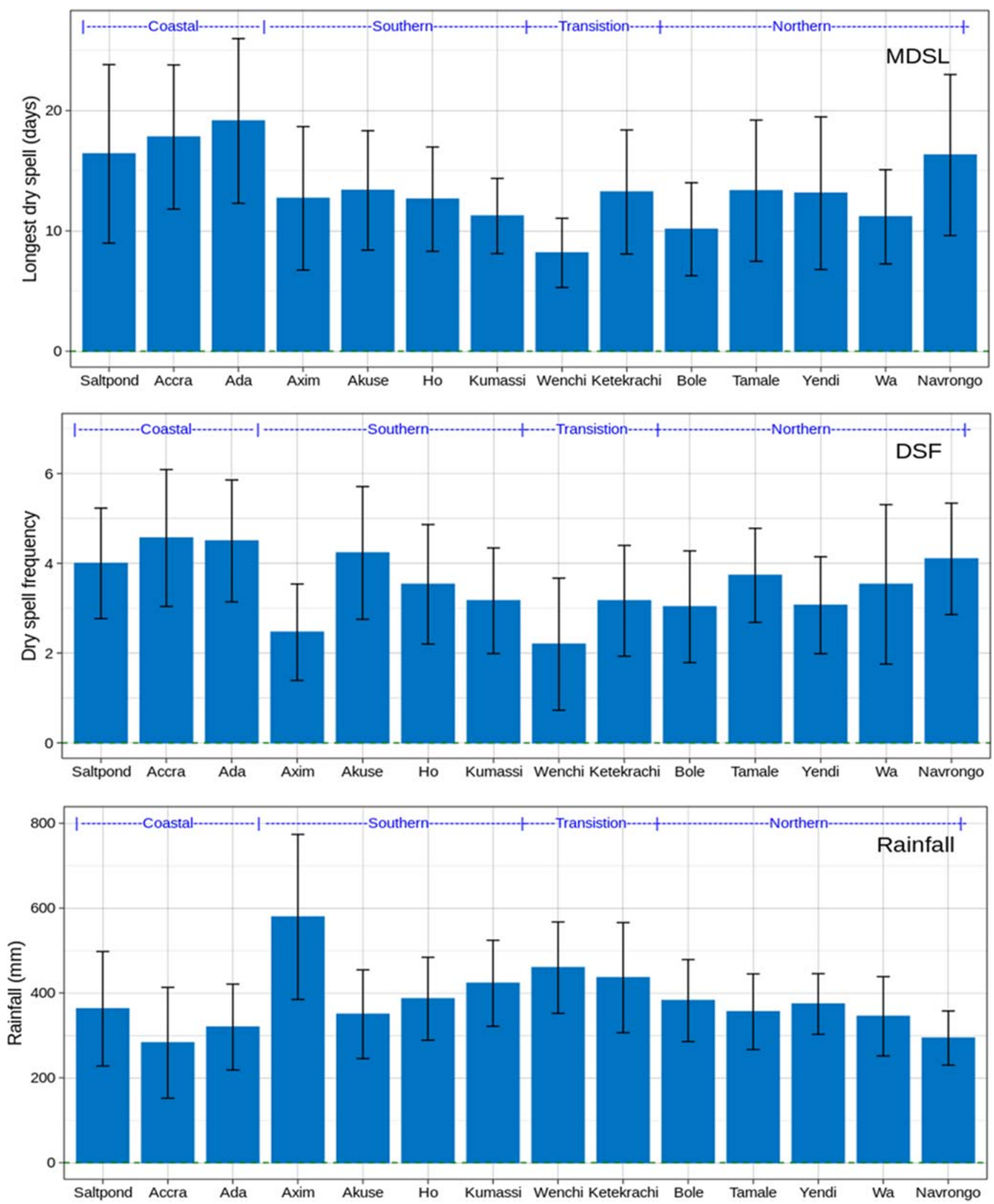

Fig. 3 Spatial variation of the climatology for the MDSL, DSF and seasonal rainfall across Ghana stations and agro-ecological zones. MAM and AMJ seasons are considered for coast-south and transition- northern agro-ecological zones, respectively. Error bars represent standard deviation of annual values of the agro-meteorological indices at each station 
range of values implies that the three observed indices (i.e. indices calculated from GMet data) have weak correlation relationship with predicted indices (i.e. agro-met indices derived from System 4 simulations). The significance test show, however, that some stations are significant. For MDSL, lead times 0,1 and 2 have, respectively, (i) 12/14, 8/14 and 10/14 fractions of stations with positive skill and (ii) $7 / 14,2 / 14$ and 2/14 fractions of stations with positive and significant skill (Fig. 4). More positive and significant stations are found in coast-south (4) as compared to the transition-north zone (2) for MDSL.

In the case of DSF (Fig. 4), lead times 0,1 and 2 count, respectively, (i) 4/14, 9/14 and 3/14 fractions of stations with positive skill and (ii) only one station with positive and significant skill. As for seasonal rainfall presented in Fig. 4, lead time 0,1 and 2 have, respectively, (i) 10/14, 11/14 and 13/14 fractions of stations with positive skills and (ii) 4/14, 1/14 and $4 / 14$ fractions of stations with positive and significant skills. A
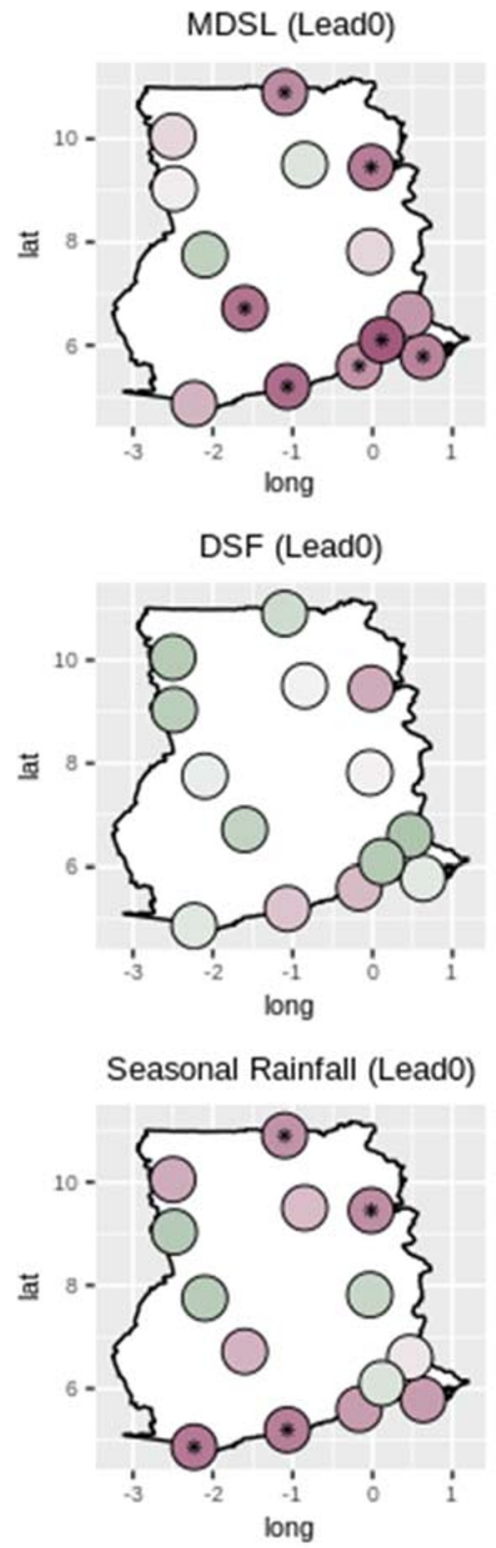
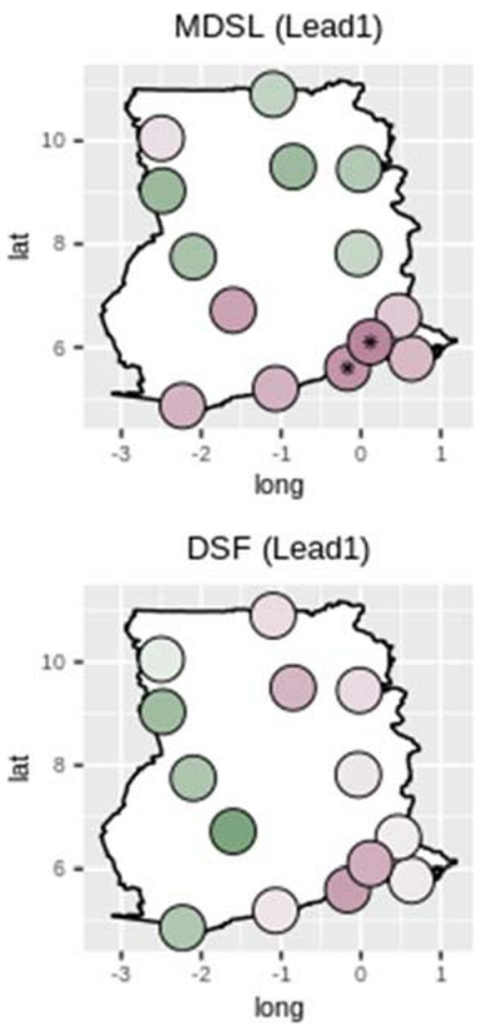

Seasonal Rainfall (Lead1)

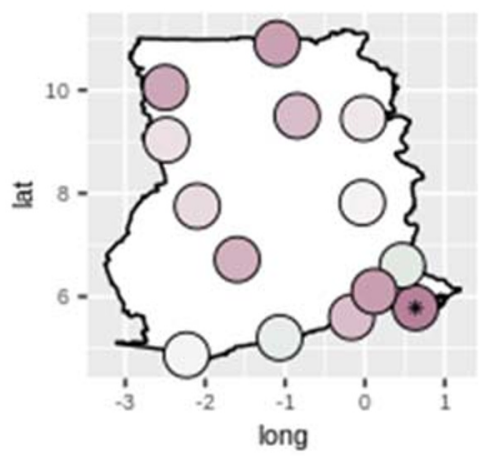

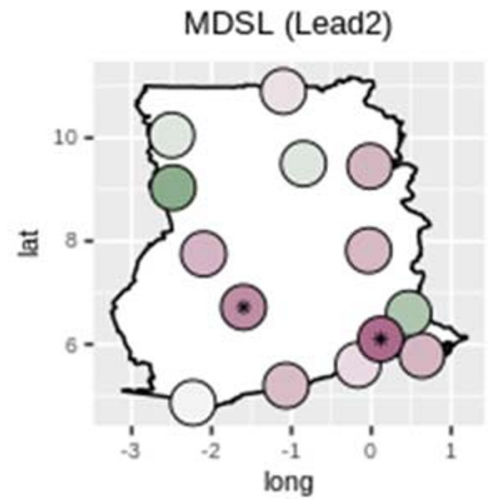

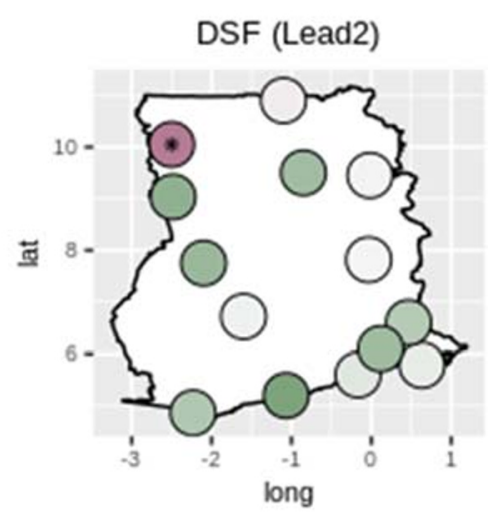

Seasonal Rainfall (Lead2)

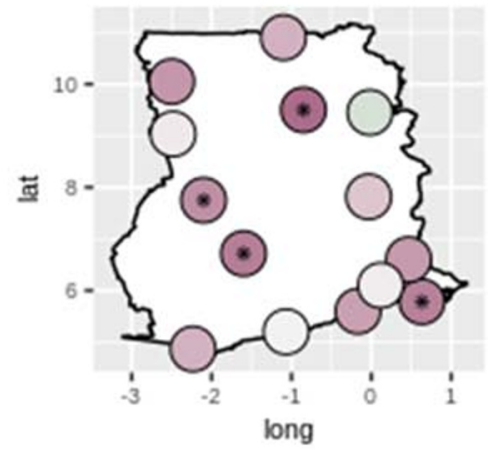

EnsCorr (GMet, System4)

Fig. 4 Ensemble correlation (EnsCorr) between GMet and the dynamical model System 4 forecasts for the maximum dry spell length (MDSL), dry spell frequency (DSF) and seasonal rainfall. Lead0, 1 and 2 represent initialisation in February (March), January (February) and December

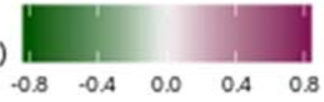

(January) considered for MAM (AMJ) seasons, respectively. Asterisk indicates the correlation significance at $p<0.10$. The overall significant EnsCorr ranges from 0.30 to 0.56 
large number of positive and significant stations are also found in the coast-south (i.e. 4) as compared to the transition-north zone (i.e. 3) for seasonal rainfall.

Summarizing, lead time 0 , generally gives the highest positive and significant skills, especially for MDSL and seasonal rainfall. The coastal south zone has a higher number of stations with positive and significant skills than the transitionnorthern zone for both MDSL and seasonal rainfall. DSF show the lowest positive and significant skills. Findings on the correlation relationship show that System 4 can explain up to $31 \%$ of the variability (i.e. correlation peaks at 0.56 ) of the indices, especially for MDSF at the coastal and southern zones.

The generalized discriminant skill score over the 14 locations ranges from 0.37 to 0.66 over lead months 0,1 and 2 (Fig. 5). Figure 5 reveals that, for MDSL, lead months 0,1 and 2 have respectively $12 / 14,8 / 14$ and $7 / 14$ fractions of stations where Ens2AFC $>0.5$. Recalling that significance for Ens2AFC cannot be tested at individual stations, the application of the binomial distribution test show that System 4 has significant skill at lead time 0 (see details in Supplemental 5, Table S2). Results for DSF and seasonal rainfall are the same as for the ensemble correlation in terms of patterns of skills (i.e. skills in DSF are the lowest and skill in seasonal rainfall is similar to that of MDSL) (see Supplemental 4, Fig. S4). Coastal savannah area, including Ada, Accra, Saltpond and Akuse, a nearby station from the southern region, shows the highest skills.

At categorical level, skilful and non-skilful categories were found over different time leads and for different agro-meteorological indices. Positive ROCSS ranges from 0 to 0.58 for MDSL (Fig. 6). The figure reveals that a large number of stations have positive skill (i.e. ROCSS $>0$ ) for the below and above normal categories (i.e. 13/14, 8/14 and $9 / 14$ fractions of stations with positive skill for lead times 0,1 and 2, respectively, for each category) in comparison to the near normal category (i.e. $9 / 14,5 / 14$ and 6/ 14 fractions of stations with positive skill for lead times 0 , 1 and 2, respectively). Also, the number of stations with significant skills is higher for below (above) normal categories (i.e. 5/14 (5/14), 4/14 (3/14) and 3/14 (5/14) for lead times 0,1 and 2, respectively) when compared to the near normal category (i.e. $1 / 14,3 / 14$ and $5 / 14$ for lead times 0,1 and 2, respectively). Additionally, the majority of stations with positive and significant skills are found in coast-south (i.e. 6 and 7 for the below and above normal categories across the lead times) compared to the transition-north zone (i.e. 4 for both below and above normal categories across the lead times) for MDSL. Results for DSF and seasonal rainfall are also the same as for the ensemble correlation in terms of patterns of the skills (i.e. skills in DSF are the lowest, whereas the skills for seasonal rainfall are similar to MDSL) (see Supplemental 6, Figs. S5 and S6). The reliability diagrams, constructed for two sample locations (Ada and Tamale) with skilful lead times (see Supplemental S7, Fig. S7), show some proximity of the curves with the perfectly reliable line and suggest that forecast probability and mean observed frequency have, relatively, good agreement.

In conclusion, the generalized and categorical skills in discriminating prolonged dry spell and seasonal rainfall are generally better than that of dry spell frequency over MAM and AMJ seasons in Ghana. System 4 performs better at distinguishing the bellow and above normal categories as it
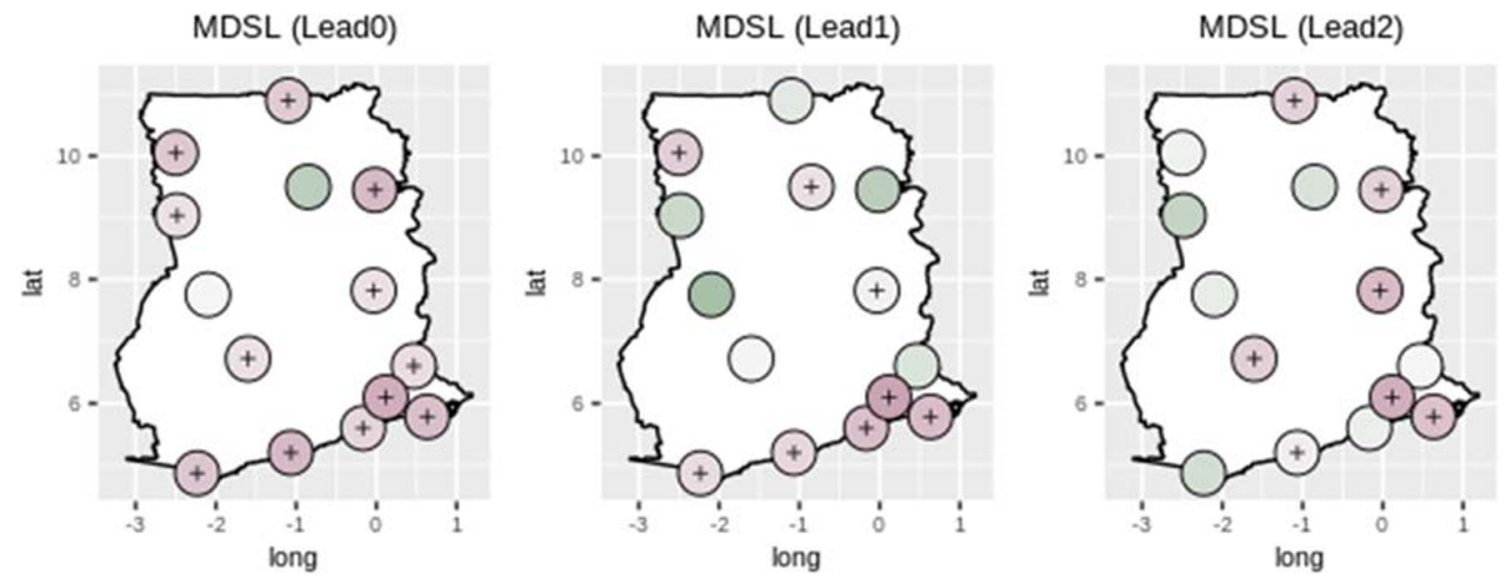

Ens2AFC (GMet, System4)

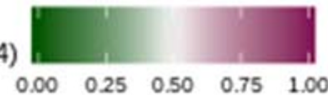

Fig. 5 Generalized discriminant score (Ens2AFC) between GMet and System 4 forecasts for the maximum dry spell length (MDSL). Lead0, 1 and 2 represent initialisation in February (March), January (February) and December (January) considered for MAM (AMJ) seasons,

respectively. Plus sign indicates the stations where Ens2AFC is greater than 0.5 (i.e. forecast better than random guessing). The overall Ens $2 \mathrm{AFC}$ scores ranges from 0.37 to 0.66 

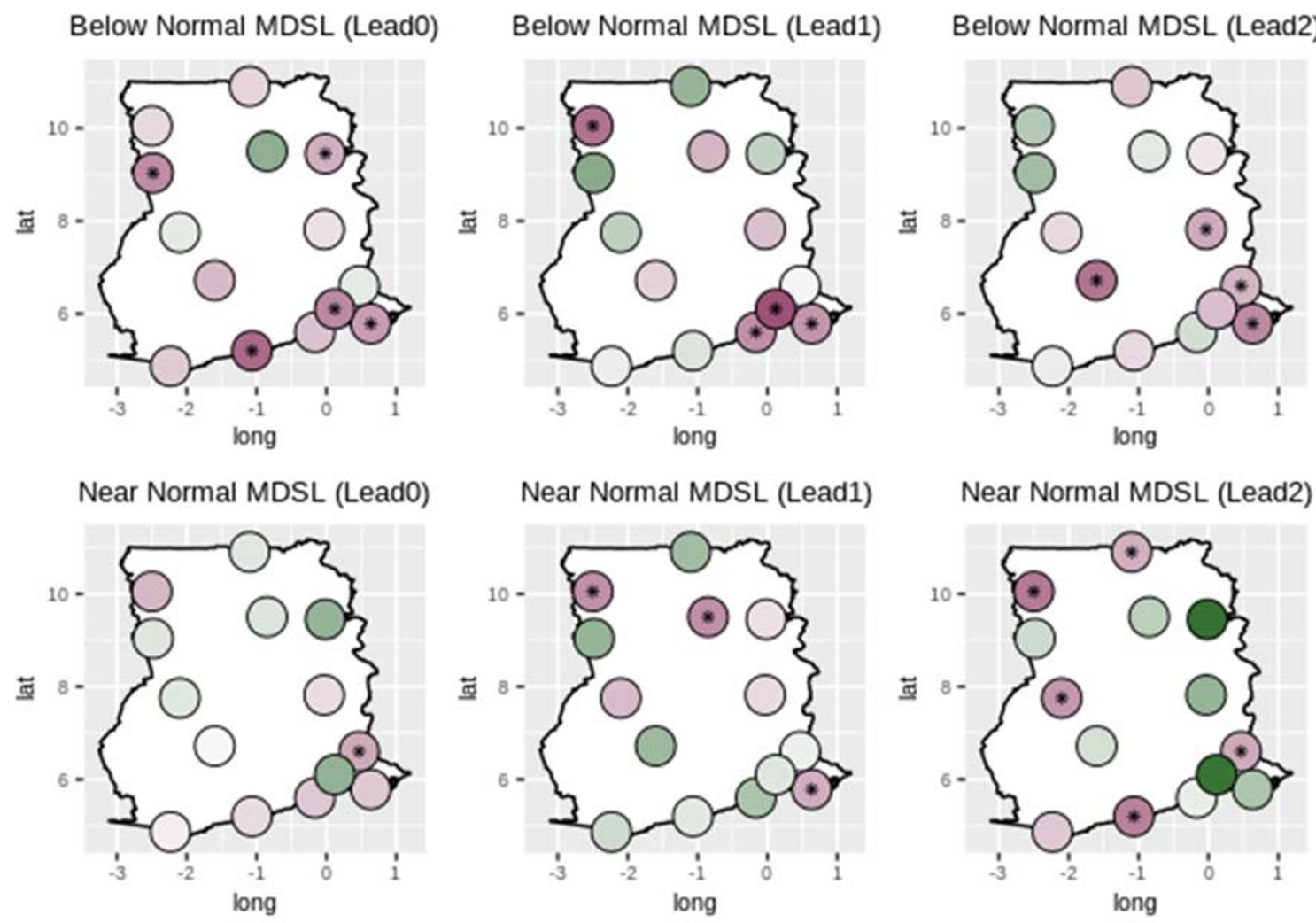

Near Normal MDSL (Lead1)

Near Normal MDSL (Lead2)
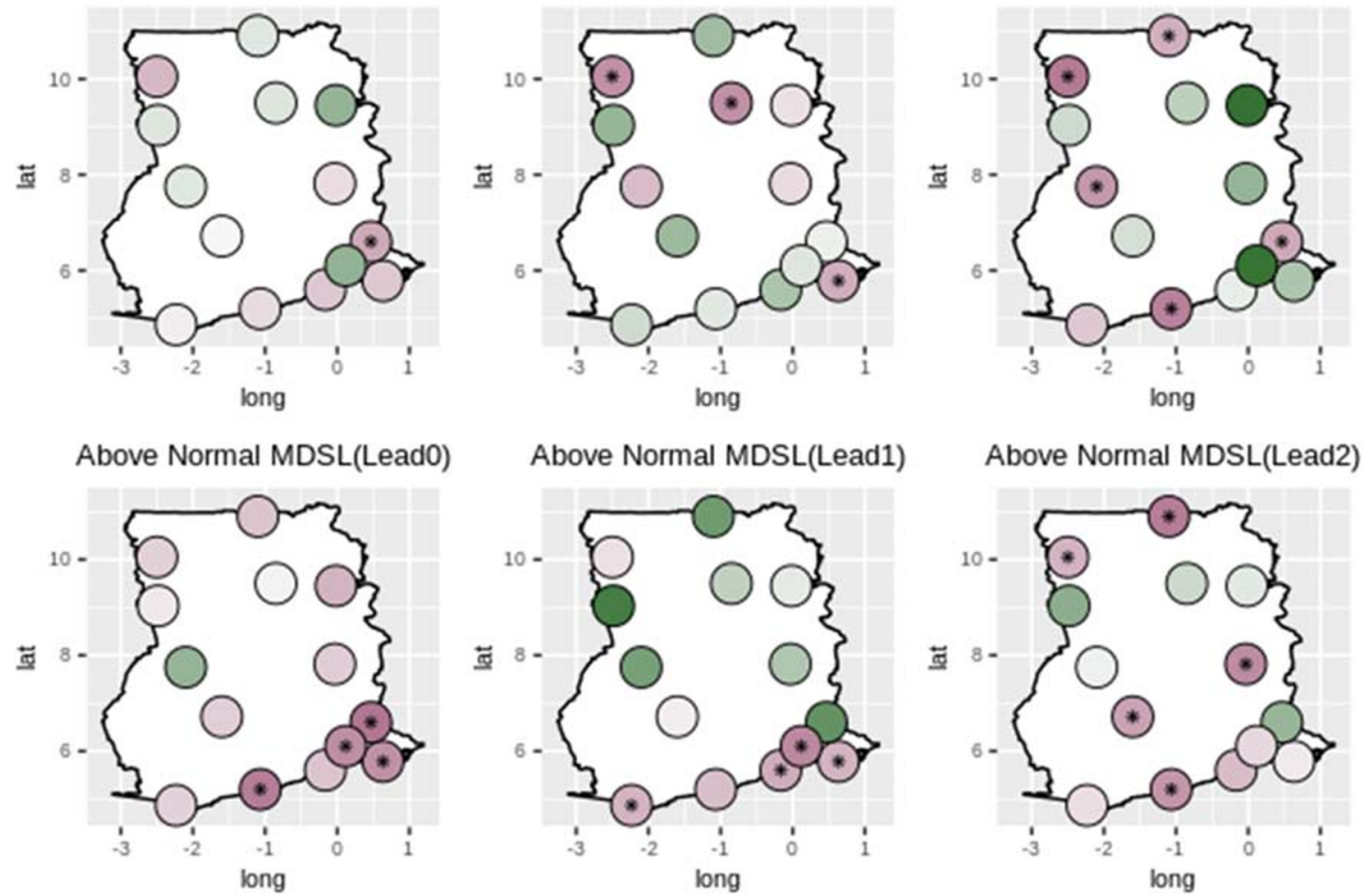

ROCSS (GMet, System4)

Fig. 6 ROCSS between GMet and the dynamical model System 4 forecasts for the maximum dry spell length (MDSL) and for the below normal, near normal and above normal categories. Lead0, 1 and 2 represent initialisation in February (March), January (February) and December $\begin{array}{lllll}-0.8 & -0.4 & 0.0 & 0.4 & 0.8\end{array}$

(January) considered for MAM (AMJ) seasons, respectively. Asterisk indicates the correlation significance at $p<0.10$. The overall positive ROCSS ranges from 0 to 0.58

\subsection{Response of seasonal rainfall and dry spell occurrence to SSTs (statistical model)}

The response of agro-meteorological indices to SAT, TSA and Niño3.4 SST is expressed as a statistical model (i.e. a linear regression model) and used to examine the seasonal prediction ability. Results presented in Fig. 7 show the spatial variation of the correlational relationship between the observed agro-meteorological indices and their 
statistical forecasts driven by the SSTs. SAT-SST tends to have weak and non-significant correlations (i.e. correlation ranging from 0 to 0.25 ) for the agro-meteorological indices with the exception of DSF which is significantly correlated with SAT-SST at (i) Ada, Tamale, Wenchi and Navrongo; (ii) Ada, Tamale and Navrongo; and (iii) Kumassi for lead months 0, 1 and 2 (Fig. 7). Compared to SAT-SST, the statistical model driven by Niño3.4-SST tends to have stronger and correlations and stations with significant correlation relationships (i.e. correlations ranging from 0.30 to 0.45 ) across lead times and Ghana (Fig. 8). This is especially the case for MDSL and applies to all lead times. Analysis for lead times longer than 2 months shows less skill (See Supplemental 8, Fig. S9). The statistical forecasts for MDSL, DSF and seasonal rainfall are all positively correlated with the observed ones across

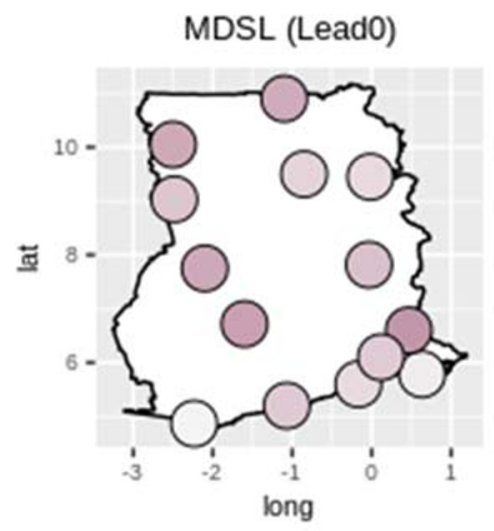

DSF (Lead0)

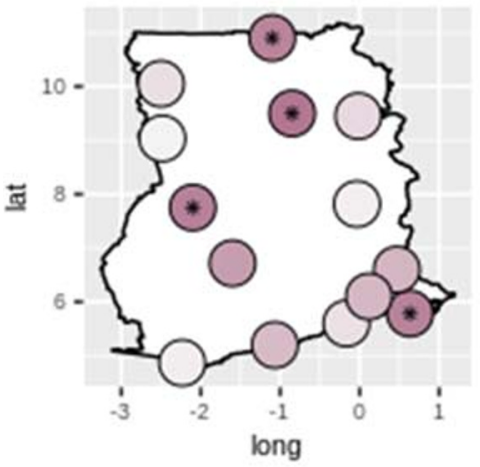

Seasonal Rainfall (Lead0)

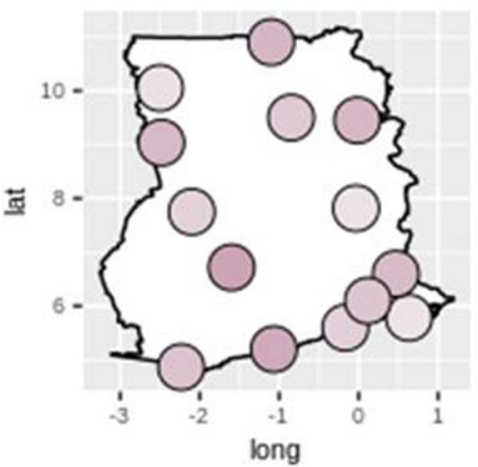

MDSL (Lead1)

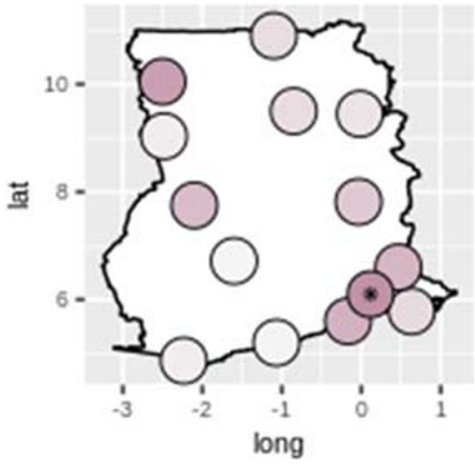

DSF (Lead1)

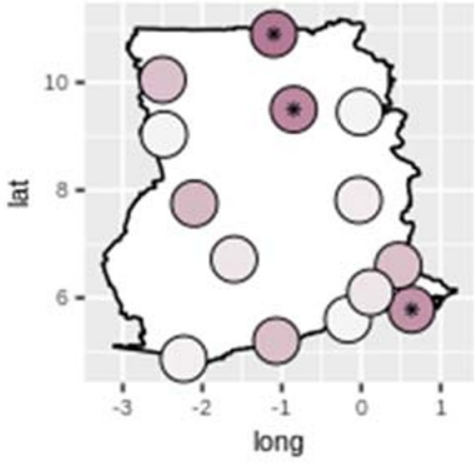

Seasonal Rainfall (Lead1)

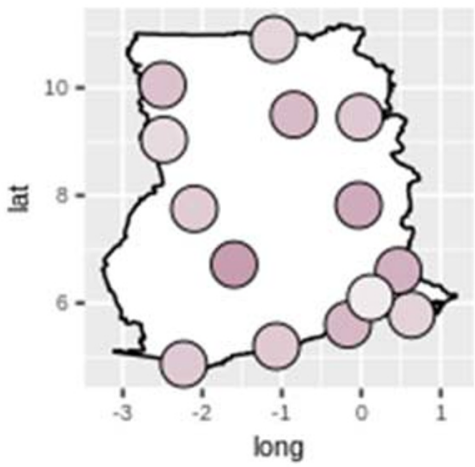

MDSL (Lead2)

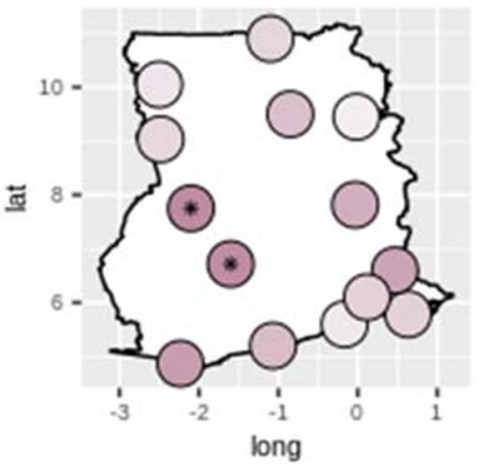

DSF (Lead2)

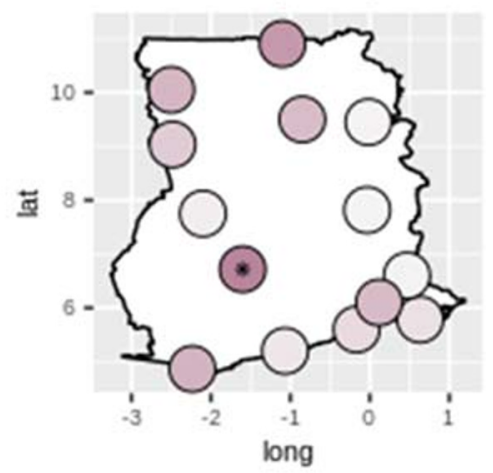

Seasonal Rainfall (Lead2)

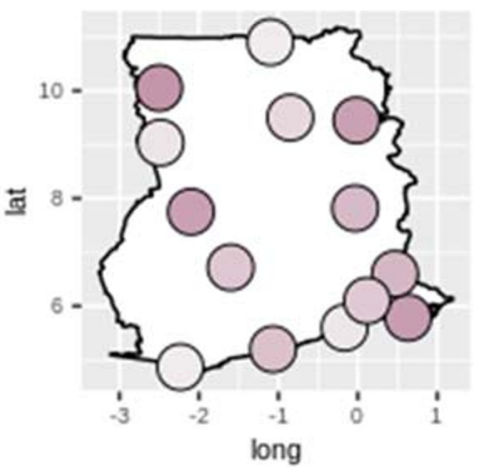

Corr (GMet, SM_SAT)

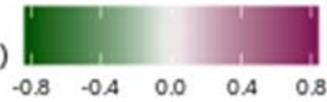

Fig. 7 Correlation between GMet and the statistical model forecasts driven by SAT-SST (SM_SAT) for the maximum dry spell length (MDSL), dry spell frequency (DSF) and seasonal rainfall. Lead0, 1 and 2 represent the relation between SSTs for February (March),
January(February) and December(January) and agro-meteorological indices considered for the MAM (AMJ) seasons, respectively. Asterisk indicates significance at $p<0.10$. The overall significant correlation coefficients range from 0.30 to 0.43 


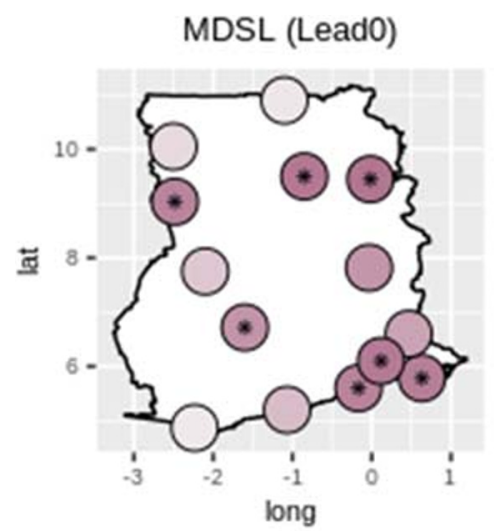

DSF (Lead0)

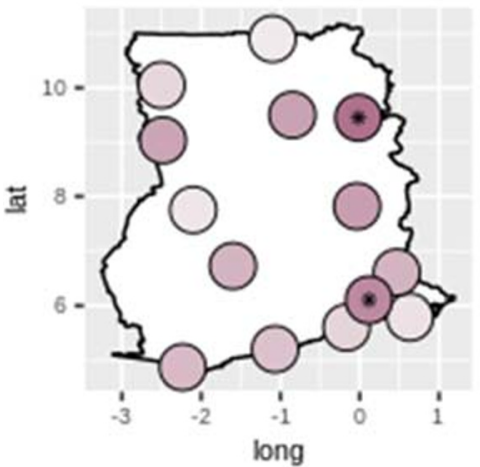

Seasonal Rainfall (Lead0)

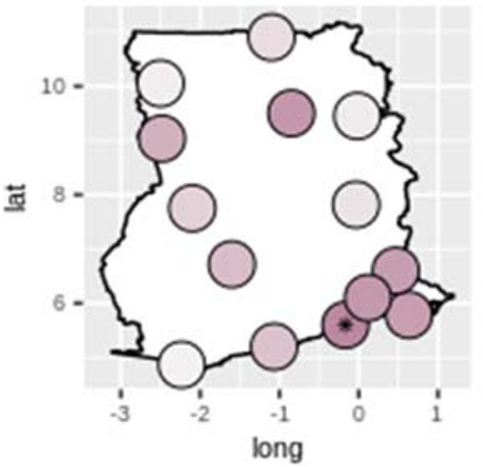

MDSL (Lead1)

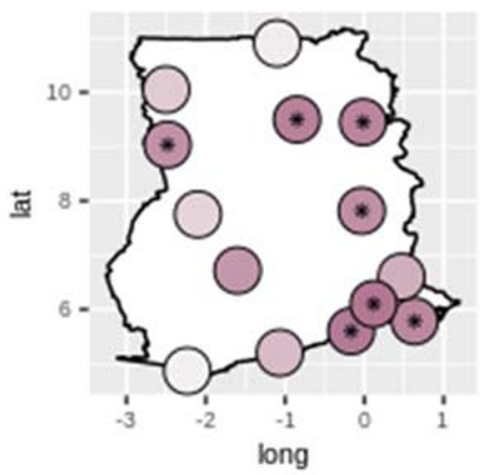

DSF (Lead1)

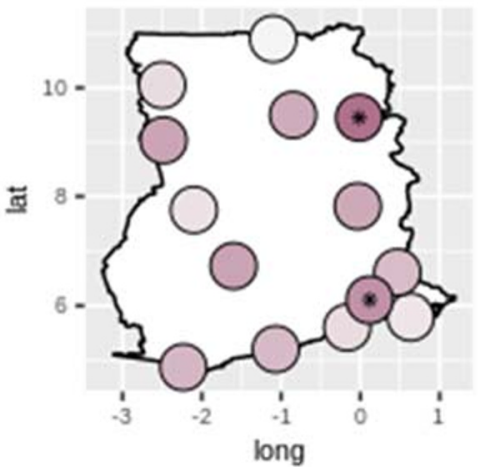

Seasonal Rainfall (Lead1)

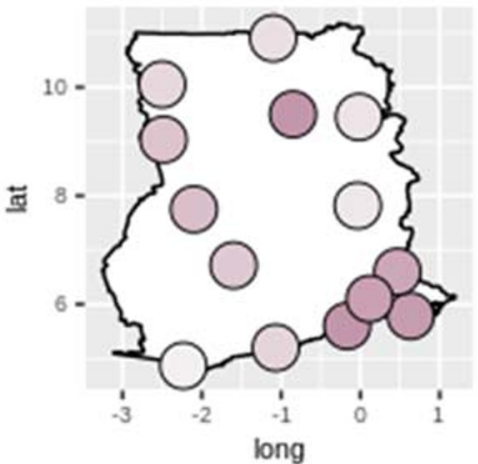

MDSL (Lead2)

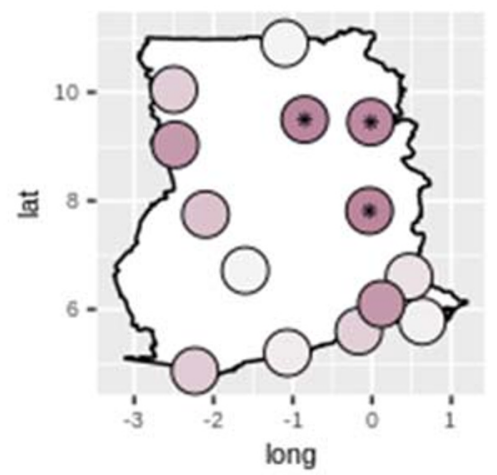

DSF (Lead2)

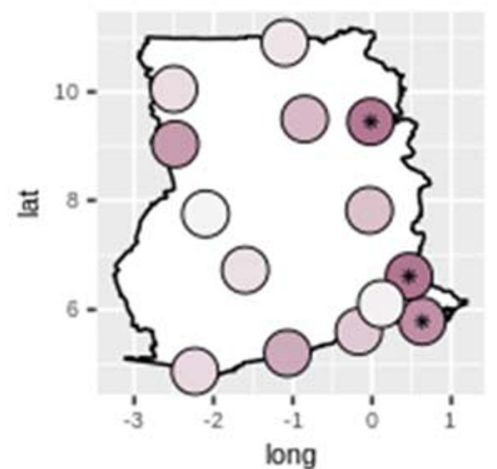

Seasonal Rainfall (Lead2)

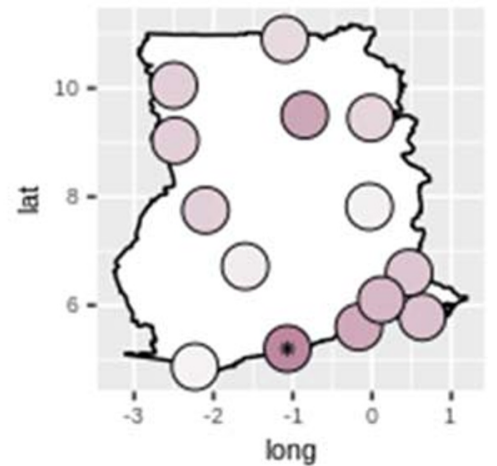

Corr (GMet, SM_Nino3.4)

Fig. 8 Correlation between GMet and the statistical model forecasts driven by Niño3.4-SST (SM_Niño3.4) for the maximum dry spell length (MDSL), dry spell frequency (DSF) and seasonal rainfall. Lead0, 1 and 2 represent the relation between SSTs for February (March),
January(February) and December(January) and agro-meteorological indices considered for MAM (AMJ) seasons, respectively. Asterisk indicates significance at $p<0.10$. The overall significant correlations coefficients from 0.30 to 0.45
Ghana. At the agro-ecological zone levels, the statistical model driven by Niño3.4-SST has more stations with significant correlations over coastal and northern for MDSL as compared to other regions. Analyses for TSASST show similar results as for SAT-SST (see Supplemental 9, Fig. S10); therefore, only SAT results are presented.
In summary, results show that the statistical model driven by Tropical Pacific SST (i.e. Niño3.4) has a better correlation relationship with local agro-meteorological indices in comparison to the Tropical Atlantic SSTs (i.e. SAT or TSA). The statistical model can explain up to $20 \%$ of the variability (i.e. correlation peaks at 0.45 ) of the agro-meteorological indices, especially for MDSL in the coastal zones. 


\subsection{Comparing the predictability of the dynamical (system 4) with the statistical model (SSTs)}

The values of significant correlation coefficients for both the dynamical model (i.e. System 4) and the statistical model (i.e. response-to-SST) have more or less the same range across Ghana (see Sects. 4.2 and 4.3). Although, the positive correlations peak at 0.56 and 0.45 for the dynamical and statistical models, respectively. Figure 9 shows the difference in correlation coefficients between the dynamical and the Niño3.4- driven statistical model. The figure indicates that the spatial distribution of significant correlations varies with lead times and agro-meteorological indices. For MDSL, the statistical model driven by Niño3.4 is more successful than the dynamical model with the exception of lead time 0 where both models have similar skill in terms of distribution of significant correlations coefficients. The statistical model is also more skilful than the dynamical one for DSF with a larger share of significant correlation coefficients. However, for seasonal rainfall, System 4 largely dominates the statistical model for
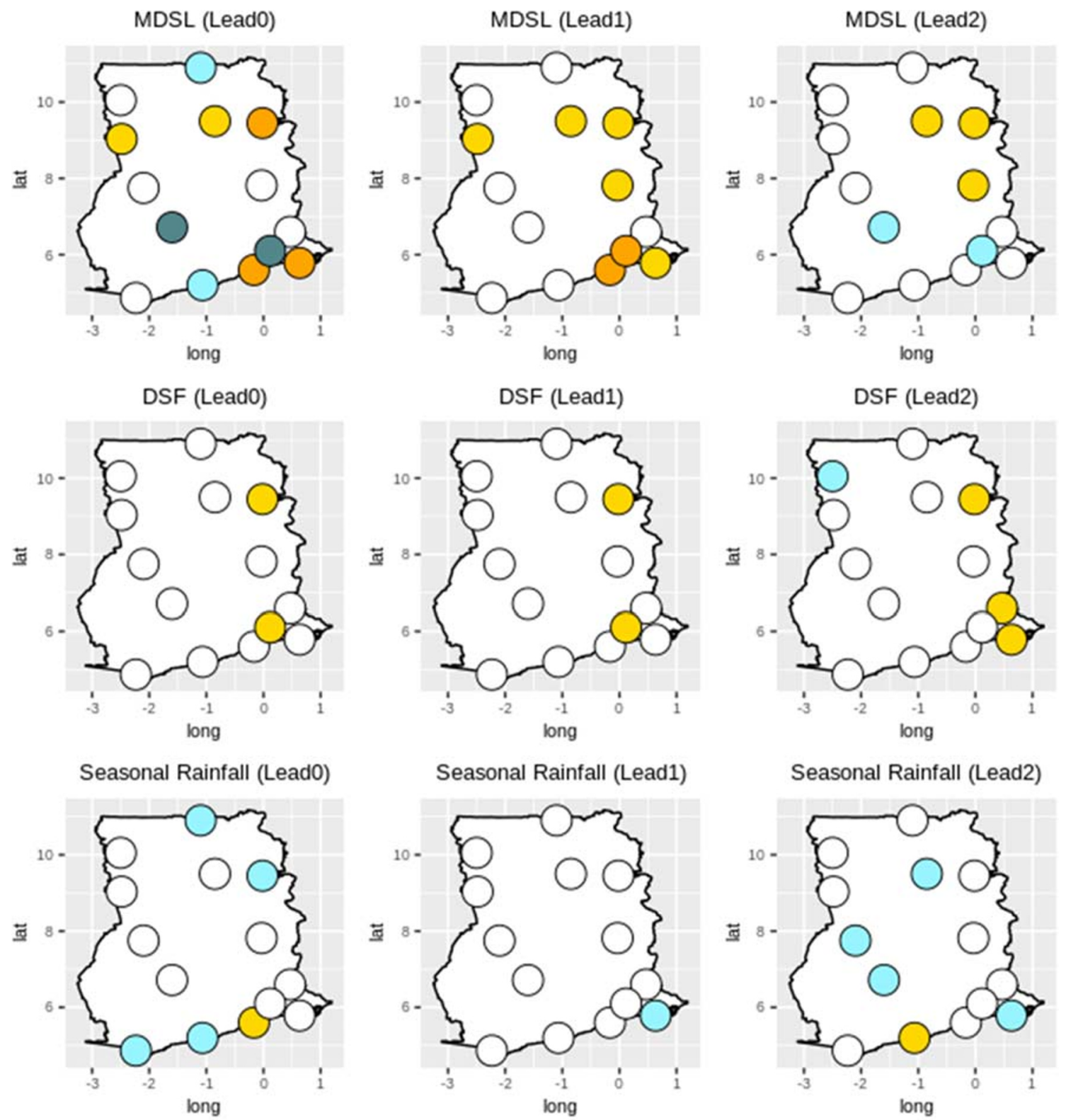

Corr. DM and SM non sig.

Corr. DM only sig.

corr. sM only sig.

Both corr. sig. with DM $>$ SM

Both corr. sig. with DM $<$ SM

Fig. 9 Comparison of the predictive skill between the dynamical model System 4 (i.e. DM) and statistical model driven by Niño3.4 (i.e. SM) in terms of difference in the correlation relationships with GMet observed agro-meteorological indices. Lead 0, 1 and 2 represent the relation between SSTs for February (March), January(February) and December(January) and agro-meteorological indices considered for MAM (AMJ) seasons, respectively. 'Corr.' and 'sig.' mean, respectively, correlation and significant 
all three lead months. The dynamical model is also more skilful than the statistical model driven by SAT for the agrometeorological indices with the exception of DSF that has more significant correlation coefficients (see Supplemental 10, Fig. S11).

The comparison reveals that the dynamical model (i.e. System 4) has, slightly, a higher predictive skill (i.e. in terms of difference in correlation coefficients) than the statistical model for MDSL and seasonal rainfall at short lead times (i.e. lead0). For longer lead times, the statistical model driven by Niño3.4 tends to perform better for MDSL. Also, DSF is better predicted by the statistical model driven by both SST indices.

\section{Discussion}

The aim of the current work was to assess the predictability of seasonal rainfall, dry spell length and frequency using local station observations as reference. In this process, both trend and interannual variability are first explored in view of ascertaining the climatic conditions prior the verification with the dynamical model (i.e. System 4). The effects of SSTs on various agro-meteorological indices are also examined as a statistical model.

\subsection{Trend, variability and predictability}

We showed that across Ghana and over the period 1981-2010, the coastal zone has the longest dry spells (i.e. MDSL) and the highest frequency of dry spells (i.e. DSF) and the lowest mean rainfall during the rainy season (i.e. MAM). It is also interesting to note that variations of the agro-met indices between zones are small in comparison to differences between stations. Both coastal and northern zones have higher variability for MDSL. Coastal zone has also the highest interannual variability in terms of seasonal rainfall. This variability ranging from 19 to $67 \%$ (Table 2) for all indices is high with reference to the study of Obarein and Amanambu (2019). These results are broadly in agreement with more recent studies on rainfall patterns over this area with large-scale dataset (Baidu et al. 2017; Atiah et al. 2019). With such level of variability, one can guess why local communities are facing challenges to make predictions based on their traditional knowledge. Over the coastal zone, the complex series of coastal/oceanic and atmospheric interactions contribute to this uncertainty (Acheampong 1982; Owusu and Waylen 2009; Manzanas et al. 2014a).

The analyses also show higher correlations between System 4 and GMet for the dry spell length and seasonal rainfall as compared to the dry spell frequency (see Sect. 4.2). The correlations found are generally weak over various stations and agro-ecological zones (i.e. correlations peaks at $0.56)$. This support the statement that seasonal forecast usually performs poorly in reproducing rainfall indices variability, including onset of the rainy season (Fitzpatrick et al. 2015; Gbangou et al. 2019). Interestingly, the coastal area, which has the highest dry spell length/lowest seasonal rainfall, was found to have the highest level of predictability in terms of correlation relationships where System 4 was able to explain up to $31 \%$ of the variability of dry spell length.

The discrimination ability of System 4 is also confirmed by the results from the Ens2AFC and ROCSS (see Section 4.3) especially for dry spell length and seasonal rainfall agrometeorological indices over the coast. Discrimination skills are shown to vary with the lead times and categories. The below and above normal categories at the majority of stations tend to have higher skills than the near normal category; this is consistent with the findings of Manzanas et al. (2014b). Results on dry spell length are also consistent with those found over another African region by Wetterhall et al. (2015). These authors also find discrimination skills for dry spell agro-meteorological indices. This implies that the use of System 4 agro-meteorological information for decision making remains better than the use of climatology or than guessing.

\subsection{Performance of the dynamical and statistical model}

Surprisingly, the statistical model (i.e. linear regression model) driven by the remote Tropical Pacific SSTs (i.e. Niño3.4-SST) showed higher correlations with local agro-meteorological indices as compared to the one driven by local (nearby) Southern Tropical Atlantic SST (SAT or TSA), especially, for MDSL and seasonal rainfall. Findings (i.e. level of correlations) with local SSTs are, however, consistent with a previous study on precipitation teleconnections over Ghana (Opoku-Ankomah and Cordery 1994). The authors showed that the relationship of local SSTs with local rainfall is strong from July to September but very weak from March to June. Our findings suggest that during the most important seasons (i.e. MAM and AMJ) where correlations with local SST are weak, farm planning can rely on predictions based on the remote SST, namely Niño3.4-SST. Although the correlations peak at 0.45 , the teleconnection is still strong enough to provide information to farmers on the likelihood of the indices during MAM and AMJ seasons (Opoku-Ankomah and Cordery 1994; Alhamshry et al. 2019).

The dynamical model explains up to $31 \%$ (i.e. correlation peaks at 0.56 ) of the variance of agro-meteorological indices while the statistical model driven by Tropical Pacific SST can only explain $20 \%$ (i.e. correlation peaks at 0.45 ) of the variance (see Sects. 4.2 and 4.3). This implies that the dynamical performs, slightly, better than the statistical model. Although both models have the same patterns of skills, that is, the same zones and indices have generally significant skills, especially, 
for dry spell length and rainfall. Also, for dry spell frequency and for longer lead time dry spell length, the statistical model tends to perform better. Skills found for longer lead times are, particularly, useful for operational purposes. The similarity in the level of skill between the response-to-SST and System 4 seasonal forecasting is probably justified, since the System 4 is also driven/initialized by SST. The difference between the dynamical and statistical models suggests that the joined use of both models can help generate more qualitative seasonal climate information.

\subsection{Importance of using local station observations and cautious interpretation of findings}

The use of local stations' observations for bias correction and skill assessment of the seasonal forecasts in this paper is a relatively new approach with strengths and challenges. The approach offers the opportunity to explore differences in forecasts skills between local stations and agro-ecological zones. By using large-scale gridded data (e.g. satellite and reanalyses), we may miss some information on local variations due to micro-scale processes (Wetterhall et al. 2015; Gbangou et al. 2019). This is the case of most previous studies that used large-scale dataset (Ogutu et al. 2017; Nyadzi et al. 2019). It is also important to consider some limitations related to the stations datasets and the methodology (Gbangou et al. 2019). The neighbour-weighted interpolation technique used to interpolate the forecast at each point station is still a form of averaging approximation that can have an effect on the results.

For dry spell and seasonal rainfall information, derived from operational dynamical forecasts, to be valuable to local farmers and water managers, the release timing restriction of the forecasts needs to be taken into account. This is because the operational forecasts from the new System (i.e. System 5) has a release date on the 5th of each month. In addition, one should consider the processing and communication time between ECMWF, the local Met agency and end-users (e.g. local farmers in Ghana). Operational statistical and dynamical forecasts with skills at long lead times offer less time restriction for the processing and communication. It is equally important to explore the predictability with more shorter term forecasts, including sub-seasonal to seasonal forecasts (1-2 months) and also weather forecasts (1-14 days) to fully meet the need of local end-users, especially in Costal delta area of Ghana.

\subsection{Implication of the findings for local farming climate services development}

With regard to farming, due to the high variability in dry spell length and frequency, and seasonal rainfall, risks of rainfed crop systems during MAM and AMJ critical growing seasons are large. One of the problems is the risk associated with crop failure during plant growing stages due to insufficient soil moisture. This can lead to a decrease in yield or generate additional costs for replanting. So far, farmers mostly relied on traditional predictions (Yaro 2013; Ingram et al. 2002; Naab et al. 2019; Antwi-Agyei et al. 2012) to appreciate the likelihood of the wet and dry seasons. Introducing modern scientific forecasts of the agro-meteorological indices can help local farmers adapt agricultural practices and hence reduce crop failure and losses, particularly in coastal and northern Ghana where Waterapps project is actively involved.

Our results show promise for the provision of some degree of skilful dry spell and seasonal rainfall forecast for local farmers in Ghana, especially during critical growing seasons. Information derived from the forecasts starting from January, February and March (coastal and southern zones) and from February, March and April (transitional and northern zones) can potentially help end-users such as local water manager and farmers with making decisions. The below and above normal information being better discriminated over the costal savannah can help to reduce the risks and costs related to crop failure through an early crop types and varieties selection. For instance, during below normal dry spell and above normal rainfall year, farmers may expect a good year. They can thus plan for early farming activities and worry less about crop failure related to water scarcity. During above normal dry spell and below normal rainfall year, there is a risk for drought. Skilful predictions could also be complemented with local traditional predictions to some extent to facilitate its acceptability and uptake (Ingram et al. 2002; Gbangou et al. 2018). However, farmers need to be well informed on the limitations of the forecasts to avoid damages related to false alarms.

\section{Conclusions}

This study has shown that there are differences in variability and skills of the agro-meteorological indices across different zones and stations that might not be noticed when using largescale datasets for forecast verification. Variations in skills between stations are higher than those between the agroecological zones which is a new insight on forecast performance at local scale. Also, similarity in skills of the agrometeorological indices over the same zones and stations are found both for the dynamical and statically models although System 4 slightly performs better, especially, for dry spell length and seasonal rainfall. For dry spell frequency and longer lead time dry spell length, the statistical model tends to perform better. The closeness in the level of skill between the response-to-SST and System 4 seasonal forecasting is probably justified, since the System is driven/initialized by SST.

Important skills in the dry spell length and seasonal rainfall forecasts with reasonable lead time are present in the coastal savannah zone. These skills are, specifically, higher for the below and above normal categories. This proves that the 
operational seasonal forecast from the updated System (e.g. System 5) and the response-to-SST can be used to provide useful information to end-users including local farmers and water managers. This finding is particularly of interest for the districts located in the coastal savannah around the delta area, namely, Ada districts, where the Waterapps project is experimenting with co-production of water information service. The provision of operational forecasts at appropriate lead times and categories in combination with the response-toSST's information can help mitigate the effect of high variability in dry spell and seasonal rainfall during critical growing stages of crops.

This new approach and understanding of the predictability could help to verify and improve agro-meteorological information in other regions affected by climate variability. Future research and application in climate services development are encouraged to explore both models (dynamical and statistical models) to improve the predictability of dry spell occurrence and seasonal rainfall information during MAM and AMJ growing seasons in Ghana.

Acknowledgements My sincerest gratitude goes Ghana Meteorological Agency (GMet) for providing gauge observations to the WaterApps project.

Funding information This research is fully funded by the Netherlands Organization for Scientific Research (NWO/WOTRO) under the urbanizing deltas of the world program (UDW) and WaterApps (www. waterapps.net) project.

Open Access This article is licensed under a Creative Commons Attribution 4.0 International License, which permits use, sharing, adaptation, distribution and reproduction in any medium or format, as long as you give appropriate credit to the original author(s) and the source, provide a link to the Creative Commons licence, and indicate if changes were made. The images or other third party material in this article are included in the article's Creative Commons licence, unless indicated otherwise in a credit line to the material. If material is not included in the article's Creative Commons licence and your intended use is not permitted by statutory regulation or exceeds the permitted use, you will need to obtain permission directly from the copyright holder. To view a copy of this licence, visit http://creativecommons.org/licenses/by/4.0/.

\section{References}

Acheampong PK (1982) Rainfall anomaly along the coast of Ghana-its nature and causes. Geografiska Annaler: Series A, Physical Geography 64:199-211

Adefolalu D (1988) Precipitation trends, evapotranspiration and the ecological zones of Nigeria. Theor Appl Climatol 39:81-89

Alhamshry A, Fenta, AA, Yasuda H, Shimizu K \& Kawai T 2019. Prediction of summer rainfall over the source region of the Blue Nile by using teleconnections based on sea surface temperatures. Theoretical and Applied Climatology, 1-11
Alizadeh-Choobari O, Adibi P, Irannejad P (2018) Impact of the El NiñoSouthern Oscillation on the climate of Iran using ERA-Interim data. Clim Dyn 51:2897-2911

Antwi-Agyei P, Fraser ED, Dougill AJ, Stringer LC, Simelton E (2012) Mapping the vulnerability of crop production to drought in Ghana using rainfall, yield and socioeconomic data. Appl Geogr 32:324 334

Atiah WA, Amekudzi LK, Quansah E, Preko K (2019) The spatiotemporal variability of rainfall over the agro-ecological zones of Ghana. Atmos Clim Sci 9(527):544

Baidu M, Amekudzi LK, Aryee J, Annor T (2017) Assessment of longterm spatio-temporal rainfall variability over Ghana using wavelet analysis. Climate 5:30

Barronfiño J (2004) Dry spell mitigation to upgrade semi-arid rainfed agriculture: water harvesting and soil nutrient management for smallholder maize cultivation in Machakos. Institutionen för systemekologi, Kenya

Codjoe SNA, Owusu G, Burkett V (2014) Perception, experience, and indigenous knowledge of climate change and variability: the case of Accra, a sub-Saharan African city. Reg Environ Chang 14:369-383

Cofiño A, Bedia J, Iturbide M, Vega M, Herrera S, Fernández J, Frías M, Manzanas R, Gutiérrez JM (2018) The ECOMS User Data Gateway: towards seasonal forecast data provision and research reproducibility in the era of climate services. Clim Serv 9:33-43

Cooper RT (2019) Projection of future precipitation extremes across the Bangkok Metropolitan Region. Heliyon 5:e01678

Diro G, Grimes DIF, Black E (2011) Teleconnections between Ethiopian summer rainfall and sea surface temperature: part I-observation and modelling. Clim Dyn 37:103-119

Fitzpatrick RG, Bain CL, Knippertz P, Marsham JH, Parker DJ (2015) The west African monsoon onset: a concise comparison of definitions. J Clim 28:8673-8694

Folland CK, Palmer TN, Parker DE (1986) Sahel rainfall and worldwide sea temperatures, 1901-85. Nature 320(602):607

Gbangou T, Ludwig F, VAN Slobbe E, Hoang L, Kranjac-Berisavljevic G (2019) Seasonal variability and predictability of agrometeorological indices: tailoring onset of rainy season estimation to meet farmers' needs in Ghana. Clim Serv 14:19-30

Gbangou T, Sylla MB, Jimoh OD, Okhimamhe AA (2018) Assessment of projected agro-climatic indices over Awun river basin, Nigeria for the late twenty-first century. Clim Chang 151:445-462

Gudmundsson L 2016. Qmap: statistical transformations for postprocessing climate model output, version 1.0-4. R package

Gudmundsson L, Bremnes J, Haugen J, Engen-Skaugen T (2012) Downscaling RCM precipitation to the station scale using statistical transformations: a comparison of methods. Hydrol Earth Syst Sci 16:3383-3390

Huang B, Banzon VF, Freeman E, Lawrimore J, Liu W, Peterson TC, Smith TM, Thorne PW, Woodruff SD, Zhang H-M (2015) Extended reconstructed sea surface temperature version 4 (ERSST. v4). Part I: upgrades and intercomparisons. J Clim 28:911-930

Ingram K, Roncoli M, Kirshen P (2002) Opportunities and constraints for farmers of West Africa to use seasonal precipitation forecasts with Burkina Faso as a case study. Agric Syst 74:331-349

Janicot S, Harzallah A, Fontaine B, Moron V (1998) West African monsoon dynamics and eastern equatorial Atlantic and Pacific SST anomalies (1970-88). J Clim 11:1874-1882

Jolliffe IT \& Stephenson DB 2012. Forecast verification, Wiley Oxford

Joly M, Voldoire A (2009) Influence of ENSO on the West African monsoon: temporal aspects and atmospheric processes. J Clim 22: 3193-3210

Jury MR, Enfield DB, Mélice JL (2002) Tropical monsoons around Africa: stability of El Niño-Southern Oscillation associations and links with continental climate. J Geophys Res Oceans 107:15-1-1517 
Li H, Sheffield J, \& Wood EF 2010. Bias correction of monthly precipitation and temperature fields from Intergovernmental Panel on Climate Change AR4 models using equidistant quantile matching. J Geophys Res: Atmospheres, 115

Manzanas R, Amekudzi L, Preko K, Herrera S, Gutiérrez J (2014a) Precipitation variability and trends in Ghana: an intercomparison of observational and reanalysis products. Clim Chang 124:805-819

Manzanas R, Frías M, Cofiño A, Gutiérrez JM (2014b) Validation of 40 year multimodel seasonal precipitation forecasts: the role of ENSO on the global skill. J Geophys Res-Atmos 119:1708-1719

Manzanas R, Gutiérrez J, Bhend J, Hemri S, Doblas-Reyes FJ, Torralba V, Penabad E, Brookshaw A (2019) Bias adjustment and ensemble recalibration methods for seasonal forecasting: a comprehensive intercomparison using the C3S dataset. Clim Dyn 53:1287-1305

Manzanas R, Gutiérrez J, Fernández J, VAN Meijgaard E, Calmanti S, Magariño M, Cofiño A, Herrera S (2018) Dynamical and statistical downscaling of seasonal temperature forecasts in Europe: added value for user applications. Clim Serv 9:44-56

Masinde M, Bagula A \& Muthama NJ 2012. The role of ICTs in downscaling and up-scaling integrated weather forecasts for farmers in sub-Saharan Africa. Proceedings of the Fifth International Conference on Information and Communication Technologies and Development, ACM, 122-129

Mason SJ 2013. Guidance on verification of operational seasonal climate forecasts. World Meteorological Organization, Commission for Climatology XIV Technical Report

Matthews AJ (2004) Intraseasonal variability over tropical Africa during northern summer. J Clim 17:2427-2440

Matthews AJ, Pickup G, Peatman SC, Clews P, Martin J (2013) The effect of the Madden-Julian Oscillation on station rainfall and river level in the Fly River system, Papua New Guinea. J Geophys ResAtmos 118:10,926-10,935

Maurer E P \& Hidalgo HG 2008. Utility of daily vs. monthly large-scale climate data: an intercomparison of two statistical downscaling methods

Mendelsohn R, Dinar A, Williams L (2006) The distributional impact of climate change on rich and poor countries. Environ Dev Econ 11: $159-178$

METEOSWISS (2017) EasyVerification: ensemble forecast verification for large data sets. R package version 0.4.2. URL: https://CRAN.Rproject.org/package=easyVerification. Accessed 2 Aug 2019

Naab FZ, Abubakari Z \& Ahmed A 2019. The role of climate services in agricultural productivity in Ghana: the perspectives of farmers and institutions. Clim Services

Nyadzi E, Werners ES, Biesbroek R, Long PH, Franssen W, Ludwig F (2019) Verification of seasonal climate forecast toward hydroclimatic information needs of rice farmers in Northern Ghana. Weather Clim Soc 11:127-142

Obarein OA, Amanambu AC (2019) Rainfall timing: variation, characteristics, coherence, and interrelationships in Nigeria. Theor Appl Climatol 137(3-4):2607-2621

Obot N, Chendo M, Udo S, Ewona I (2010) Evaluation of rainfall trends in Nigeria for 30 years (1978-2007). Int J Physical Sci 5:2217-2222

Ogutu GE, Franssen WH, Supit I, Omondi P, Hutjes RW (2017) Skill of ECMWF system-4 ensemble seasonal climate forecasts for East Africa. Int J Climatol 37:2734-2756
Opoku-Ankomah Y, Cordery I (1994) Atlantic Sea surface temperatures and rainfall variability in Ghana. J Clim 7:551-558

Owusu K, Waylen P (2009) Trends in spatio-temporal variability in annual rainfall in Ghana (1951-2000). Weather 64:115-120

Owusu K, Waylen PR (2013) The changing rainy season climatology of mid-Ghana. Theor Appl Climatol 112:419-430

Partal T, Kahya E (2006) Trend analysis in Turkish precipitation data. Hydrol Process 20:2011-2026

Reynolds RW, Rayner NA, Smith TM, Stokes DC, Wang W (2002) An improved in situ and satellite SST analysis for climate. J Clim 15: $1609-1625$

Rowell DP (2001) Teleconnections between the tropical Pacific and the Sahel. Q J R Meteorol Soc 127:1683-1706

Siegert S 2017. SpecsVerification: forecast verification routines for ensemble forecasts of weather and climate. R package version $0.5-2$. URL: https://CRAN.R-project.org/package=SpecsVerification. Accessed 2 Aug 2019

Sultan B, Janicot S (2003) The West African monsoon dynamics. Part II: the "preonset" and "onset" of the summer monsoon. J Clim 16: 3407-3427

Themeß1 MJ, Gobiet A, Heinrich G (2012) Empirical-statistical downscaling and error correction of regional climate models and its impact on the climate change signal. Clim Chang 112:449-468

Usman MT, Reason C (2004) Dry spell frequencies and their variability over southern Africa. Clim Res 26:199-211

Vellinga M, Arribas A, Graham R (2013) Seasonal forecasts for regional onset of the West African monsoon. Clim Dyn 40:3047-3070

Vitart F, Ardilouze C, Bonet A, Brookshaw A, Chen M, Codorean C, Déqué M, Ferranti L, Fucile E, Fuentes M (2017) The subseasonal to seasonal (S2S) prediction project database. Bull Am Meteorol Soc 98:163-173

Voisin N, Schaake JC, Lettenmaier DP (2010) Calibration and downscaling methods for quantitative ensemble precipitation forecasts. Weather Forecast 25:1603-1627

Weigel AP, Mason SJ (2011) The generalized discrimination score for ensemble forecasts. Mon Weather Rev 139:3069-3074

Wetterhall F, Pappenberger F, He Y, Freer J, Cloke H (2012) Conditioning model output statistics of regional climate model precipitation on circulation patterns. Nonlinear Process Geophys 19:623-633

Wetterhall F, Winsemius H, Dutra E, Werner M, Pappenberger E (2015) Seasonal predictions of agro-meteorological drought indicators for the Limpopo basin. Hydrol Earth Syst Sci 19(2577):2586

Wood AW, Maurer EP, KumarA \& Lettenmaier DP 2002. Long-range experimental hydrologic forecasting for the eastern United States. J Geophys Res: Atmospheres, 107

Yaro JA (2013) The perception of and adaptation to climate variability/ change in Ghana by small-scale and commercial farmers. Reg Environ Chang 13:1259-1272

Zhang Q, Holmgren K, Sundqvist H (2015) Decadal rainfall dipole oscillation over southern Africa modulated by variation of austral summer land-sea contrast along the East Coast of Africa. J Atmos Sci $72: 1827-1836$

Publisher's note Springer Nature remains neutral with regard to jurisdictional claims in published maps and institutional affiliations. 